\title{
A tutela do direito dos refugiados no Brasil: uma perspectiva a partir da Luta por Reconhecimento
}

\author{
The Protection of Refugee Rights in Brazil: A Perspective From The Struggle for Recognition
}

\author{
Rute Oliveira Passos*
}

\author{
Clara Cardoso Machado Jaborandy ${ }^{* *}$
}

Dimas Pereira Duarte Júnior ${ }^{* * *}$

\begin{abstract}
REFERÊNCIA
PASSOS, Rute Oliveira; JABORANDY, Clara Cardoso Machado; DUARTE JÚNIOR, Dimas Pereira. A tutela dos refugiados no Brasil: uma perspectiva a partir da luta por reconhecimento. Revista da Faculdade de Direito da UFRGS, Porto Alegre, n. 41, p. 145-164, dez. 2019. DOI: <https://doi.org/10.22456/0104-6594.84682>.
\end{abstract}

\section{RESUMO}

O presente artigo analisa a situação dos refugiados através da perspectiva teórica da Luta por Reconhecimento do filósofo Axel Honneth, que propõe uma reflexão subjetiva do seu próprio pertencimento e à determinada comunidade e como vê os seus direitos protegidos por ela. Nesse diálogo, não há de forma predominante uma análise dos aspectos simplesmente jurídicos, pois até mesmo estes podem falhar na devida proteção da pessoa humana, mas em aspectos intersubjetivos, através da psicologia social que, na existência de conflitos, ensejem uma postura emancipatória do indivíduo frente a omissões de reconhecimento de direitos. Objetiva-se com este trabalho observar outros instrumentos para efetivação e garantia dos Direitos Humanos das pessoas que se encontram em situação de refúgio. Para o seu desenvolvimento, utilizou-se o método qualitativo bibliográfico, através na análise da situação dos refugiados sob um aspecto de efetivação dos seus direitos no plano da "luta por reconhecimento". Nesta perspectiva, diante da ineficácia dos instrumentos normativos estatais em atender à grande demanda que as migrações forçadas impõem, em especial, as solicitações de refúgio, necessário requerer da sociedade uma mudança de paradigma que até então, não tem sido destacado como mecanismo essencial para as mudanças globais, pautadas na verificação do indivíduo como agente principal de transformação social através do reconhecimento.

\section{PALAVRAS-CHAVE}

Direitos Humanos. Reconhecimento. Refugiados.

\begin{abstract}
This article analyzes the situation of refugees through the theoretical perspective of the Struggle for Recognition of the philosopher Axel Honneth, who proposes a subjective reflection of his own belonging and
\end{abstract}

\footnotetext{
* Mestranda em Direitos Humanos pela Universidade Tiradentes. Graduada em Direito. Pesquisadora da Universidade Tiradentes. Integrante do Grupo de Pesquisa "Novas tecnologias e o impacto nos Direitos Humanos".

** Doutora em Direito pela Universidade Federal da Bahia. Mestre em Direito pela Universidade Federal da Bahia. Pós-graduada em Direito público pela Uniderp. Graduada em Direito pela Universidade Federal de Sergipe. Professora do Mestrado em Direitos Humanos da Universidade Tiradentes e de cursos de Graduação e pós-graduação da Universidade Tiradentes, Ciclo Renovando Conhecimentos e EJUSE. Coordenadora do grupo de pesquisa Fundamentais, Novos Direitos e Evolução Social. Advogada militante em Direito Público. Vicepresidente da Comissão de Estudos Constitucionais da OAB/SE.

* Doutor em Ciências Sociais: Relações Internacionais pela Pontifícia Universidade Católica de São Paulo PUC-SP (2008). Mestre em Filosofia Política pela Universidade Federal de Goiás (2001). Professor e Pesquisador do Mestrado em Direitos Humanos da Universidade Tiradentes - UNIT/SE
} 
the determined community and how he sees his rights protected by it. In this dialogue, there is not predominantly an analysis of the simply legal aspects, since even these can fail in the proper protection of the human person, but in intersubjective aspects, through social psychology that, in the existence of conflicts, give rise to an emancipatory posture of the individual against omissions of recognition of rights. The objective of this text is to observe other instruments to guarantee and guarantee the Human Rights of people who are in a refuge situation. For its development, the qualitative bibliographical method was used, through the analysis of the situation of the refugees under an aspect of the realization of their rights in the "struggle for recognition". In this perspective, in view of the inefficiency of state normative instruments in meeting the great demand that forced migration imposes, in particular, refugee requests, it is necessary to require from society a paradigm shift that hitherto has not been singled out as an essential mechanism for global changes, based on the verification of the individual as the main agent of social transformation through recognition.

\section{KEYWORDS}

Human Rights. Recognition. Refugees.

\section{SUMÁRIO}

1 Introdução. 2. A Proteção Legal dos Refugiados na Esfera Nacional e Internacional. 3. O Processo de Reconhecimento dos Refugiados a partir da Teoria de Axel Honneth. 4. Considerações Finais. Referências. Dados da publicação.

\section{INTRODUÇÃO}

O fenômeno das migrações forçadas no mundo não é recente, ocorre no âmbito global muito antes do advento das guerras mundiais, como também, do próprio reconhecimento dos Direitos Humanos como tema universal, em que se transfere de uma problemática de tratamento doméstico para uma perspectiva global. Contudo, apesar de tão antigo, as discussões sobre os refugiados sempre se demonstram contemporâneas, tendo em vista que, até então, discute-se a responsabilidade do Estado de proteger, e, consequentemente, da sociedade de acolher e reconhecer o direito dos estrangeiros em qualquer lugar do mundo. Nesse debate, envolve-se a soberania dos Estados, a proteção dos seus territórios e a possibilidade de se haver ingerência de organismos internacionais nos assuntos internos a fim de trazer a efetividade mínima de proteção internacional dos direitos humanos em favor dos refugiados.

No entanto, para o Alto Comissariado das Nações Unidas (ACNUR), não tem sido tarefa fácil, vez que, as migrações forçadas refletem a situação conflituosa na qual estão inseridos vários Estados, em que a preocupação com a dignidade da pessoa humana se encontra como último item na pauta dos assuntos políticos internos. Nesse mesmo contexto, há que se ressaltar que a sociedade internacional também não tem dado a devida atenção aos temas globais de violação aos direitos humanos.

Em uma era considerada globalizada, em que há liberdade de ir e vir, as ações democráticas e o acesso à informação estão mais facilitados, aflorando-se socialmente um sentimento individualista, em que os problemas dos outros dizem respeito apenas aos outros, 
mesmo se tratando de questões de reconhecimento de direitos inerentes à pessoa humana, e que sofrem ameaças independentemente da nacionalidade, raça, gênero, condição socioeconômica, dentre outras condições privadas.

Diante desse cenário em que se encontram inseridas as problemáticas sociais, diante da proposta existente no sistema do direito internacional, vislumbra-se a impossibilidade das ações estatais alcançarem todas as demandas, principalmente no que diz respeito a situações transnacionais. Desta forma, propõe-se a ideia de responsabilidade social, que, por uma série de fatores foi omitida por muito tempo, tendo como consequência uma sobrecarga das atribuições estatais, enquanto, socialmente, se espera que sejam efetivados de forma adequada as garantias de proteção à pessoa humana.

Ressalvadas as reais atribuições do Estado, compreende-se que cada indivíduo tem obrigações como sujeito pertencente de uma comunidade, no sentido de trazer a promoção de direitos, partindo dos seus deveres correlatos e autônomos. Não se trata de realizar atribuições de encargos estatais, mas sim, de exercer o seu papel político social, que parte de um reconhecimento próprio de capacidades para transformação, a fim de reivindicar direitos ainda não alcançados pelos demais componentes da sociedade.

Nesse contexto, o presente trabalho inicialmente analisa os aspectos principais da proteção global dos Direitos Humanos, com ênfase nas proteções nacionais, internacionais e regionais das pessoas em situação de refúgio, questionando desta forma, quais as reais dificuldades enfrentadas pelo sistema global de proteção, retratadas pela grande aumento dos fluxos migratórios no mundo devido a maciça violação dos direitos humanos, e a crescente continuidade de surgimento de populações nestas condições, sem terem o devido acesso aos mecanismos de proteção.

Em seguida, frente às referidas questões, propõe o trabalho um diálogo com a obra do filósofo e sociólogo alemão Axel Honneth "A luta por reconhecimento: a gramática moral dos conflitos sociais", em que, dando continuidade aos estudos de Friedrich Hegel e George Herbert Mead, enfatiza a possibilidade do indivíduo reconhecer-se no outro, através de um processo de luta partindo de um comportamento intersubjetivo para efetivação de direitos. Cumpre destacar, que se trata de uma perspectiva baseada na teoria crítica, em que se reconhece primordialmente a participação social do indivíduo para tornar eficaz os mecanismos estatais na proteção de direitos.

Através da pesquisa qualitativa e bibliográfica, baseada na análise de relatórios nacionais e globais que retratam a situação contemporânea dos refugiados, o estudo foi 
desenvolvido elucidando a dificuldade de se garantir a efetiva proteção dos refugiados de apenas através da atuação estatal. Assim, propõe o trabalho um diálogo com os aspectos teóricos da obra de Axel Honneth, analisando uma intersecção do mecanismo individual - o reconhecimento, como meio de garantir a proteção e efetividade do direito internacional dos refugiados.

Em se tratando da perspectiva global da situação dos refugiados, entende-se a indispensável compreensão social do perfil inerente ao indivíduo em situação de refúgio, em que, a sua situação é agravada quando em meio a uma sociedade individualista, é tratado de forma hostil, como se não tivesse lugar algum no mundo. Desta forma, propõe-se uma ressignificação do próprio "Eu" como sujeito de direitos, para reconhecer-se no outro, a fim de tornar a vida em sociedade, através da proteção dos direitos humanos das pessoas refugiados, digna e no pleno exercício dos direitos humanos.

\section{A PROTEÇÃO LEGAL DOS REFUGIADOS NA ESFERA NACIONAL E INTERNACIONAL}

Conforme leciona Cançado Trindade (1996), o sistema de proteção internacional para refugiados é indissociável da constituição do Direito Internacional, do Direito Humanitário e do Direito Internacional dos Direitos Humanos (DIDH). A Carta da Organização das Nações Unidas (ONU) como marco jurídico para a instrumentalização de um Direito Internacional foi baseada no ideal de uma possível e harmônica convivência entre os Estados devidamente reconhecidos, resguardando a soberania de cada um, tendo como princípios fundamentais a autodeterminação dos povos e a proibição de ingerência externa nos assuntos domésticos das nações.

Contudo, nesse mesmo aspecto, se tem a necessidade de trazer instrumentos normativos de proteção à pessoa humana, esta que, não obstante a sua integração na cidadania do Estado na qual é pertencente, diante das preocupações apenas políticas, muitos direitos se encontravam mitigados diante da ausência de instrumentos nacionais e internacionais que defendem efetivamente os Direitos Humanos. Através da Declaração Universal dos Direitos Humanos (1948), que posteriormente foi justicializada pelos Pactos de 1966, possibilitou-se o surgimento de um sistema global de proteção internacional dos Direitos Humanos. Além disso, com a instituição dos sistemas regionais, envolvendo o continente africano, americano e 
europeu, em que, através deles, buscou-se uma aproximação das peculiaridades de cada região para serem atendidas pela proteção jurídica internacional dos Direitos Humanos ${ }^{1}$.

Piovesan (2017, p.357) ensina que, além desses instrumentos, fora reiterado na Declaração de Direitos Humanos de Viena (1933) que "Todos os direitos humanos são universais, interdependentes e interrelacionados. A comunidade internacional deve tratar os direitos humanos globalmente de forma justa e equitativa, em pé de igualdade e com a mesma ênfase", ou seja, a reafirmação da interdependência da tríade dos valores dos direitos humanos, democracia e desenvolvimento.

De igual forma se tem a proteção internacional dos refugiados, com abrangência global, regional e nacional, tendo como órgão de monitoramento internacional o Alto Comissariado das Nações Unidas (ACNUR), com competência para acompanhar o cumprimento e efetivação dos mecanismos globais em favor das pessoas em situação de Refúgio.

O marco jurídico da proteção internacional dos refugiados através de uma instrumentalização propriamente dita de um Direito Internacional dos Refugiados (DIR) inicia-se no pós-Segunda Guerra Mundial, através da Convenção Relativa ao Estatuto dos Refugiados de 1951. Ressalvadas as suas limitações temporais e geográficas, surge então o Protocolo Adicional de 1967 que torna o sistema de proteção mais abrangente, trazendo ao plano prático a real situação dos refugiados no mundo que não estava restrita ao continente europeu, muito menos ao lapso temporal até 1951. Sobre o ACNUR, destaca Almeida (2015) que "com a elaboração da Convenção de Genebra de 1951 e do Protocolo de 1967, estavam prontos os principais documentos jurídicos do DIR; restava a criação de um organismo responsável para aplicar esses instrumentos" (ALMEIDA, 2015, p. 95).

Nessa mesma perspectiva de aprimoramento de mecanismos e do sistema internacional de proteção aos refugiados, observou-se a necessidade de trazer uma proteção regional para complementar os instrumentos globais. Na região Africana, a Organização de Unidade Africana (OUA) celebra a Convenção de 1960, dando uma compreensão mais extensiva a conceituação do termo "refugiado", em condições não atendidas pelo sistema global. No

\footnotetext{
${ }^{1}$ Conforme explica categoricamente Guilherme Almeida a respeito da composição do DIDH: “A Carta da ONU (1945) a Declaração Universal dos Direitos Humanos (1948), o Pacto Internacional de Direitos Civis e Políticos (foi adotado em 1966 e entrou em vigor em 1976; atualmente tem 168 ratificações), e o Pacto In- ternacional de Direitos Econômicos, Sociais e Culturais (foi adotado em 1966 e entrou em vigor em 1976; atualmente conta com 162 ratificações) formam, em seu conjunto, a Carta da ONU de Direitos Humanos, documento básico do DIDH. " (ALMEIDA, 2015, p. 42). $8^{\prime} \sim c ̧$
} 
contexto latino-americano tem-se a Convenção de Cartagena (1984) ${ }^{2}$, que compreende disposições que estabelecem mecanismos mais eficazes de proteção dos refugiados dos países dessa região em cooperação com o ACNUR.

Em uma perspectiva nacional, não apenas no que diz respeito à proteção dos Refugiados, mas em diversas modalidades de proteção de minorias, o Brasil sempre foi elogiado perante os organismos internacionais, por trazer instrumentos legais avançados e que conseguem abranger as diversas peculiaridades individuais que enfrentam os detentores dos direitos humanos. Claro que, a efetividade desses instrumentos através das políticas públicas nacionais aplicadas merece outra extensa discussão, porém, até então, o país tem demonstrado empreender esforços no sentido de estar sempre aprimorando a legislação nacional para atender as demandas sociais que envolvem as pessoas solicitantes de refúgio.

Nesse sentido, além de ter os instrumentos globais de proteção aos refugiados ratificados no país, recentemente o Brasil promulgou uma nova Lei de Migração (Lei 13.4445/2017) que se propõe a aperfeiçoar os sistemas já existente. Para além disso existem resoluções normativas elaboradas pelo Ministério da Justiça e o Comitê Nacional para Refugiados (CONARE) que têm o condão de aprimorar cada vez mais o sistema nacional de proteção às pessoas em situação de refúgio. Além de instalar duas sedes no ACNUR, o país conta com organismos da sociedade civil que auxilia o engajamento estatal para dar o devido acolhimento aos imigrantes e refugiados, como a Cátedra Sérgio Vieira de Melo e a Cáritas Arquidiocesana de São Paulo.

Não obstante a existência de todo um arcabouço jurídico administrativo de proteção aos Refugiados, inúmeras são as dificuldades enfrentadas pelo país em relação à condição dessas pessoas, tendo em vista que, trata de uma situação que não envolve somente a atuação estatal, mas a sociedade como um todo. Nesse contexto, os principais problemas enfrentados pelos refugiados no Brasil atualmente são de receber um devido acolhimento, como também, através das políticas públicas estatais se utilizarem de mecanismos de empoderamento para dar continuidade às suas vidas, sem necessitar depender exclusivamente dos benefícios da assistência social do Estado.

\footnotetext{
2 “A Declaração de Cartagena recomendava que, além daquelas hipóteses normais de reconhecimento da condição de refugiados, os países deveriam incorporar aos seus ordenamentos jurídicos o conceito de refugiado, também, a toda aquela pessoa que tivesse fugido de seu país porque a sua vida, segurança ou liberdade tenham sido ameaçadas pela violência generalizada, agressão estrangeira ou conflitos internos, violação maciça dos direitos humanos ou outras circunstâncias que tenham perturbado gravemente a ordem pública". (BARRETO, 2010, p. 16).
} 
Em se tratando de temas globais, especificamente sobre os Refugiados, dificilmente seria possível exaurir todas as dificuldades enfrentadas no contexto de reconhecer socialmente os direitos das pessoas nessas condições. Contudo, destaca-se nesse estudo três problemas que conseguem dialogar diretamente com a proposta aqui estudada que diz respeito ao dever de reconhecimento do indivíduo frente às necessidades do outro.

Inicialmente a problemática que está atrelada ao sentimento do medo do desconhecido, que resulta em um comportamento hostil frente aos imigrantes, independentemente da modalidade de migração. Em seguida, vislumbra-se a ineficiência dos instrumentos legais hábeis a encontrar efetividade no plano práticos das demandas sociais dos refugiados. E, por fim, a necessidade de atenção ao posicionamento dos países de acolhida dado às pessoas que se encontram em situação de refúgio, que se apresentam, por vezes, como uma nova forma de violação de direitos humanos.

Em primeiro lugar, a ainda predominante hostilidade na qual os cidadãos do Estado acolhedor, em condutas caracterizadas como xenófobas esquivam-se de reconhecer em favor dos que solicitam refúgio. Nesse sentido, já advertia Kant (1989), para que não houvesse a confusão entre o reconhecimento de direitos e o comportamento voluntário de benevolência. Nas palavras de Kant (1989, p.37), "trata-se aqui não de filantropia [...], mas do direito, e hospitalidade significa, aqui, o direito de um estrangeiro, por conta de sua chegada à terra de um outro, de não ser tratado hostilmente por este". Tal comportamento é incentivado também pela própria legislação nacional.

Não obstante a existência de instrumentos legais modernos e avançados, em uma análise crítica a respeito dos seus reais fundamentos, observa-se que há mais objetivos de se esquivar do dever de hospitalidade e tudo que dele decorre, do que propriamente de reconhecimento de direitos.

Conforme leciona Igor Machado (2016, p.213), há um “princípio de imobilidade espalhado por toda a legislação: o excesso de documentos, a necessidade regular de comparecer à Polícia Federal, a proibição da mudança, o impedimento até da mudança de emprego". Ou seja, há um compartilhamento de condutas hostis, tanto do próprio Estado, quanto da sociedade.

Em terceiro lugar, e ainda de forma associada às duas anteriores problemáticas, observase que "os imigrantes se colocam como elementos vivos e vulneráveis nesse cenário reificante em mutação, que exige uma reformulação radical de suas próprias bases normativas que fundamentam seus arcabouços institucionais e humanos" (FERREIRA, 2017, p. 54). Assim, 
quando fogem de violação das mais diversas maneiras no seu país de origem, não podem sofrer tais violações reiteradas no país de acolhimento. Contudo, ainda salta aos olhos uma cultura de desrespeito, de pena e desprezo aos solicitantes de refúgio, moldada por discursos políticos e midiáticos equivocados, e que acabam por ensejar a ausência de reconhecimento do outro como sujeito de direitos.

\section{O PROCESSO DE RECONHECIMENTO DOS REFUGIADOS A PARTIR DA TEORIA DE AXEL HONNETH}

Os temas globais não têm se esquivado da situação que o mundo tem enfrentado no que diz respeito ao grande fluxo migratório envolvendo as condições elementares do refúgio ${ }^{3}$, não se tratando especificamente de um problema sem regulamentação, mas sim, de se estabelecer uma atuação doméstica adequada para enfrentar as peculiaridades que ensejam tal temática. Ultrapassada a discussão da responsabilidade estatal, que advém da celebração de tratados e convenções internacionais, diante da fragilidade que se encontra tal cenário, importa observar mecanismos subsidiários, não menos importantes, mas que têm sido por vezes deixado de lado nas discussões sobre questões globais de ordem tão complexa.

Mas não se pode desconsiderar que, conforme preconiza Santos e Chauí (2013, p. 80), "qualquer que seja o seu âmbito, as transformações ocorrem primeiro na lei e só muito lentamente vão influenciando as instituições e conformando as mentalidades e subjetividades"

${ }^{4}$. Nesse sentido, diante de um arcabouço de instrumentos legais que até então tem atendido formalmente as demandas que veem surgindo com o advento de fluxos migratórios nas mais diversas partes do mundo, questiona-se porque o sistema de proteção às pessoas em condição de refúgio se mostra tão deficiente ${ }^{5}$.

\footnotetext{
3 A Convenção de 1951 relativa ao Estatuto dos Refugiados define o instituto do refúgio como sendo: “Que, em consequência dos acontecimentos ocorridos antes de $1^{\circ}$ de janeiro de 1951 e temendo ser perseguida por motivos de raça, religião, nacionalidade, grupo social ou opiniões políticas, se encontra fora do país de sua nacionalidade e que não pode ou, em virtude desse temor, não quer valer-se da proteção desse país, ou que, se não tem nacionalidade e se encontra fora do país no qual tinha sua residência habitual em consequência de tais acontecimentos, não pode ou, devido ao referido temor, não quer voltar a ele.”. Ignorando aqui a limitação temporal, esta suplantada pelo Protocolo Adicional de 1966.

4 Boaventura Sousa Santos e Marilena Chauí (2013, p. 125) lecionam categoricamente a importância de se preocupar com as questões de violação a direitos, partindo de uma consciência crítica que resulte em ação contrária a essas opressões, enfatizando que "a desumanidade e a indignidade humana não perdem tempo a escolher entre as lutas para destruir a aspiração humana da humanidade e de dignidade. $\mathrm{O}$ mesmo deve acontecer com todos os que lutam para que tal não aconteçam".

5 Segundo Relatório do ACNUR/Brasil juntamente com o CONARE e o Ministério da Justiça, até o final de 2017, o Brasil havia reconhecido 10.145 refugiados de diversas nacionalidades. Do total, $52 \%$ desse quantitativo
} 
Para tal questão, não há uma resposta simples e objetiva que consiga atender satisfatoriamente a cada problemática que a questão abrange. Contudo, cumpre mencionar em termos gerais que, o sistema de proteção internacional dos direitos humanos há muito tempo vem sendo criticado por sofrer ausência de efetividade ${ }^{6}$, sendo mais explicitamente verificado como um conjunto de instrumentos normativos baseados em atuações por parte de potências mundiais com interesses políticos e econômicos, do que propriamente, com a dignidade e proteção da pessoa humana.

Tendo em vista as várias nuances que envolvem a dificuldade de se garantir e efetivar os direitos humanos, dentre as perspectivas do que realmente são direitos humanos e para quem são direcionados, encontram-se discussões filosóficas no intuito de propor medidas ainda não tão evidenciadas socialmente e que trabalham mais com a emancipação do indivíduo frente às questões sociais, do que simplesmente com a sua dependência das atuações estatais. Tal condição é introduzida por Amartya Sen (2010), quando propõe um ideal para os indivíduos de se proporem na sua comunidade como agente de transformação social, sendo um componente responsável pela mudança do cenário em que há maciça violação de direitos.

Todavia, esse posicionamento, apesar de demonstrar-se complementar ao reconhecimento de direitos humanos, precisa passar por um longo processo de consciência subjetiva, em que, além do desenvolvimento de autonomia por parte do indivíduo, a mudança social só será efetivada quando, além do próprio reconhecimento de direitos, estes poderem ser reconhecidos em favor do outro, trazendo assim uma ideia de reverberação do que se vê identificado no plano individual a fim de transcender para o plano coletivo.

moram em São Paulo, 17\% no Rio de Janeiro e $8 \%$ no Paraná. Os sírios representam 35\% da população de refugiados com registro ativo no Brasil. O ano de 2017 foi o maior em número de pedidos de refúgio, desconsiderando a chegada dos venezuelanos e dos haitianos que retratam uma mudança significativa nos índices anteriormente apontados. Foram 13.639 pedidos no ano de 2017, 6.287 em 2016, 13.383 em 2015 e 11.405 em 2014. No total, 33.866 pessoas solicitaram o reconhecimento da condição de refugiado no Brasil em 2017. Os venezuelanos representam mais da metade dos pedidos realizados, com 17.865 solicitações. Na sequência estão os cubanos (2.373), os haitianos (2.362) e os angolanos (2.036). Os estados com mais pedidos de refúgio são Roraima (15.955), São Paulo (9.591) e Amazonas (2.864), segundo dados da Polícia Federal. (BRASIL, 2017).

6 "Há algo muito atraente na ideia de que qualquer pessoa, em qualquer lugar no mundo, independentemente de nacionalidade, local de domicílio, cor, classe, casta ou comunidade, possui alguns direitos básicos que os outros devem respeitar. O grande apelo moral dos direitos humanos tem sido usado para várias finalidades, desde a resistência à tortura, à prisão arbitrária e a discriminação racial até a exigência de eliminar a fome, a miséria e a falta de assistência médica em todo o planeta. Ao mesmo tempo, muitos críticos consideram totalmente desprovida de fundamento a ideia básica de que os indivíduos têm direitos humanos simplesmente por ser humanos. As perguntas mais frequentes são: esses direitos existem? De onde eles provêm? ". (SEN, 2011, p. 390). 
O reconhecimento dos direitos humanos na perspectiva internacional, como marco legal para a proteção da dignidade da pessoa humana, já se encontra em uma fase de ressignificação, ou seja, uma reconstrução de direitos como colocado por Celso Lafer (1995), quando trata dos aspectos de ruptura e de novas concepções dos direitos humanos. Por outro lado, dados os devidos reconhecimentos pelos entes da comunidade internacional, questionase oportunamente onde estão atrelados os deveres humanos a serem observados por cada indivíduo, este também, sujeito de direitos na órbita global.

Necessário se faz destacar que o termo “deveres humanos" se impõe na presente discussão como medida indispensável em que proporciona uma ressignificação da ideia de promoção de direitos humanos e mecanismos de garantir a sua efetividade ${ }^{7}$. Não se propõe deixar de lado a devida responsabilidade dos Estados e da comunidade internacional como um todo de preservar a humanidade dos flagelos que podem comprometer todo o seu futuro, conforme prelecionado na Carta das Nações Unidas (ONU, 1945). Porém, insere-se nos temas globais a necessidade de emancipação do indivíduo para que este tenha capacidade de, como sujeito de direitos na comunidade internacional, participar ativamente do reconhecimento, promoção e garantia dos seus direitos e dos direitos da sua comunidade.

Essa abordagem é pontuada por Jaborandy (2017), ao tratar a fraternidade como um princípio jurídico, dando ênfase a atuação do indivíduo em comunidade para proteção de direitos, mesmo diante da ineficiência dos mecanismos estatais. Tal posicionamento esclarece a necessidade de conscientizar indivíduos a terem condutas ativas em relação a ineficácia da proteção de direitos, que decorrem das próprias deficiências dos institutos políticos-jurídicos (as chamadas políticas de Governo e políticas de Estado). Desta forma, a autora propõe "uma (re) inserção da fraternidade no direito" (JABORANDY, 2017, p. 9) como medida para alcance do bem-estar social.

\footnotetext{
${ }^{77}$ Diante do recorte metodológico o presente trabalho não adentrará a discussão da temática dos deveres, porém, dentre os trabalhos que fazem referência aos deveres fundamentais destacam-se: PECES-BARBA MARTÍNEZ, Gregorio. Los deberes fundamentales. Doxa, Alicante, n. 4,1987; NABAIS, José Casalta. O dever fundamental de pagar impostos. Coimbra: Livraria Almedina, 1998. NABAIS, José Casalta. A face oculta dos direitos fundamentais: os deveres e os custos dos direitos. In: Estudos de direito fiscal. Coimbra: Almedina, 2005, p. 939. ANDRADE, José Carlos Vieira de. Os direitos fundamentais na Constituição portuguesa de 1976. $3^{\mathrm{a}}$ ed. Coimbra: Almedina, 2007. CANOTILHO, José Joaquim Gomes. Direito constitucional: e teoria da constituição, $7^{a}$ ed. Coimbra: Almedina, 2003. MAINO, Carlos Alberto Gabriel. Derechos fundamentales y la necesidad de recuperar los deberes: aproximación a la luz del pensamiento de Francisco Puy. In: LEITE, George Salomão. SARLET, Ingo Wolfgang. CARBONELL, Miguel (Coord). Direitos, deveres e garantias fundamentais. Salvador: Juspodium, 2011. SARLET, Ingo Wolfgang. A eficácia dos direitos fundamentais: uma teoria geral dos direitos fundamentais na perspectiva constitucional. Porto Alegre: Livraria do Advogado, 2010. MARTINS, Carlos Eduardo Behrmann Rátis. Introdução ao estudo sobre os deveres fundamentais. Salvador: JusPodivm, 2011.
} 
Assim, a proposta atende " a possibilidade de se extrair do princípio da fraternidade um conteúdo jurídico apto à concretização de interesses Transindividuais através da ação estatal e da responsabilidade dos indivíduos em comunidade". (JABORANDY, 2017, p. 7). Com isso, já se adianta a ideia de desencargo das obrigações estatais, que seria inclusive, um contrassenso, ao retornar à ideia absenteísta do Estado Liberal. A fraternidade proposta, é um instrumento a ser utilizado pelo indivíduo em consonância com a atuação estatal. Logo, uma atuação não substitui a outra.

Insere-se nessa perspectiva, o "reconhecimento" proposto por Axel Honneth (2003), que a partir de Hegel, preconiza tal mecanismo como processo de luta para em um plano ético compreender os conflitos sociais. Em um sentido mais próximo da temática global de migrações forçadas, o reconhecimento está atrelado a condutas que busquem compreender efetivamente a condição de refúgio, reconhecer-se como sujeito de direitos e deveres na comunidade internacional, e frente a uma solicitação de refúgio, encontrar-se o indivíduo em uma posição de dever de reconhecimento, ou seja, reconhecer-se em uma situação de refúgio, para promover a devida proteção ao solicitante.

A teoria da "luta por reconhecimento" funda-se em uma tríade que equivale ao amor, ao direito e à estima social, sendo sua correspondência aos respectivos desrespeitos que fazem surgir os conflitos sociais e motivam ações intersubjetivas (HONNETH, 2003, p. 24). Tais ações podem ser compreendidas pela insatisfação individual frente a desconsideração dessa tríade, requerendo uma mudança social que será adquirida através de processos de luta. Contudo, não é um processo simples. Faz-se necessário de antemão haver uma emancipação individual a fim de que se persiga o reconhecimento "do outro como um fim em si mesmo", no contexto em que, o desrespeito ao outro, seja encarado como um desrespeito a si mesmo, fazendo com que isso reverbere em uma automática reflexão e luta contra tal imposição.

Importa destacar que esse dever não supre as obrigações do Estado, mas possui um caráter suplementar, pois, diante de uma concepção em que o indivíduo é parte de uma constituição social, deve agir como tal, participando precipuamente do reconhecimento de direitos de sujeitos, ainda que alheios a sua realidade. Essa engenhosidade propõe uma mudança de paradigma, ou seja, um novo olhar para as questões sociais, partindo de uma concepção "intersubjetiva" a fim de compreender subjetividades.

O processo de reconhecimento, em se tratando da questão específica dos refugiados, deve ir além de uma perspectiva intracomunidade, ou seja, inserido apenas em um ambiente em que as pessoas tenham afinidade ou interesses em comum, mas parte-se de uma concepção 
de reconhecimento do outro como ser humano, não restringindo esse reconhecimento a uma nacionalidade. Se não há o reconhecimento além da comunidade, não há que se falar em enxergar o outro como processo de identificação de si mesmo. O processo de reconhecimento nesse escopo encara uma outra esfera de complexidade, quando parte de um reconhecimento de direitos. Honneth (2003) aponta que, "os direitos são de certa maneira as pretensões individuais das quais posso estar seguro que o outro generalizado as satisfará", porém, nessa perspectiva, tais pretensões se inserem apenas em um caráter de comunidade particular.

Diante disso, questiona-se a possibilidade de uma luta de reconhecimento em favor de sujeitos fora do espectro comunitário, ou seja, reconhecer como sujeito de direitos e lutar pelo direito de pessoas que estão alheias ao plano comum de reconhecimento. Nessa concepção, o autor faz uma reflexão através dos estudos da psicologia do teórico da psicologia social G. H. Mead, através da observância a formação da identidade humana, afirmando que

[...] se o mecanismo de desenvolvimento da personalidade consiste em que o sujeito aprende a conceber-se a si mesmo desde a perspectiva normativa de seu defrontante, então, o círculo de parceiros de ação, o quadro de referência de sua auto-imagem prática deve também se ampliar gradativamente. (HONNETH, 2003, p. 134).

A teoria crítica que é base para o desenvolvimento da discussão colocada por Honneth (2003) é fundada "[...] na ideia de que a possibilidade da sociedade emancipada está inscrita na forma atual de organização social sob a forma de uma tendência real de desenvolvimento". (HONNETH, 2003, p. 9). Nesse mesmo sentido, compreende a teoria crítica como uma orientação para emancipação contra a dominação, partindo de uma concepção de que a sociedade tem maior desenvolvimento através de ações em conjunto. Assim, há uma quebra das teorias tradicionais pré-concebidas em direção a um pensamento crítico e reflexivo. Essa proposta é realizada através de uma continuação dos estudos "fracassados" "8 de Hegel e Mead, sendo o primeiro no campo da sociologia e o segundo no campo da psicologia social, em que ambos os teóricos não conseguiram trazer a proposta do reconhecimento para o plano das ações sociais.

Tal pensamento se alinha com as discussões de Amartya Sen (2010), em sua obra Desenvolvimento como Liberdade, em que, parte da ideia central de que o indivíduo essencialmente deve estar inserido em condições de emancipação política e democrática para

\footnotetext{
8 Justifica Honneth a ideia do fracasso dos teóricos que embasaram a sua tese, pelo seguinte motivo: "tanto o jovem Hegel quanto Mead quiseram pensar o futuro da sociedade moderna de modo que ela suscitasse um sistema de valores novo, aberto, em cujo horizonte os sujeitos aprendessem a se estimar reciprocamente em suas metas de vida livremente escolhidas [...]". Ou seja, um contexto voltado para a solidariedade, mas sem levar em consideração o conteúdo prático que aduz a viabilidade do pensamento solidário entre indivíduos devidamente emancipados.
} 
transformar as problemáticas sociais solucionáveis através de um plano de atividades em conjunto. Parte-se, portanto, de uma concepção de comprometimento social do sujeito, em um contexto propenso para que as próprias pessoas estejam conscientes da responsabilidade de desenvolver e mudar o mundo em que vivem. Ou seja, "não é tanto uma questão de ter regras exatas de como exatamente devemos agir, e se de reconhecer a relevância de nossa condição humana para fazer as escolhas que se nos apresentam", em circunstâncias de comprometimento e responsabilidade social (SEN, 2010, p. 359-350).

Compreende-se, nessa esteira, a contemporânea pertinência da teoria da "luta por reconhecimento" em se tratando das concepções sociais sobre as migrações forçadas ${ }^{9}$, especificamente sobre os refugiados, em um contexto em que, supera-se a ideia Maquiavel que "enxerga o estado bruto de toda a vida social, porque elas não designam nada mais que os pressupostos estruturais da ação bem-sucedida por poder" (HONNETH, 2003, p. 33) - e a supremacia dos interesses estatais através da soberania, colocado posteriormente por Hobbes ${ }^{10}$.

Através da concepção hegeliana, Honneth (2003) retrata a ineficácia da luta social através dos parâmetros jurídicos impostos “[...] pois, numa organização social caracterizada por formas jurídicas de reconhecimento, os sujeitos não estão constitutivamente incluídos senão mediante liberdades negativas, ou seja, meramente com a sua capacidade de negar ofertas sociais". Nesse aspecto, não é negar a importância dos instrumentos normativos, mas, reiterar que a sua imposição não corresponde ao reconhecimento voluntário do indivíduo a fim de torná-lo eficaz em favor do outro.

\footnotetext{
${ }^{9}$ No âmbito das migrações forçadas, podemos extrair desse termo duas espécies: o asilo e o refúgio. Porém, diante da confusão terminológica dos próprios instrumentos legais, Guilherme de Assis Almeida prefere definir que, "o asilo é gênero que possui duas espécies: o asilo político e o estatuto do refugiado. Uma diferença fundamental entre asilo e estatuto do refugiado refere-se ao âmbito geográfico de sua aplicação. O asilo é um instituto jurídico regional, estando instituído apenas na América Latina, enquanto o estatuto do refugiado é aplicado internacionalmente.”. (ALMEIDA, 2015, p. 85).

10 Essa acepção é colocada pelo autor em um contexto social de "autoconservação", em que [...] os escritos políticos de Maquiavel preparam a concepção segundo o qual os sujeitos individuais se contrapõem numa concorrência de interesses, não diferentemente de coletividades políticas; na obra de Hobbes, ela se torna enfim a base de uma teoria do contrato que fundamenta a soberania do Estado". (HONNETH, 2003, p. 31). Contrário a esse posicionamento e alinhado a concepção Kantiana de uma perspectiva de comunidade global, preleciona Celso Lafer 'O 'interesse' de um tratado de direitos humanos concebido como 'tema global' situa-se no campo dos valores, nas formas democráticas de conceber a vida em sociedade, pressupondo que a violação de direitos humanos fere a soberania popular porque compromete a perspectiva dos governados, a perspectiva ex parte populi, vista como superior à perspectiva ex parte principis. Em outras palavras, a associação entre democracia e direitos humanos significa que existe uma relação entre o ciclo do poder e o ciclo da norma, na qual a legitimidade do poder e a justiça da norma e de sua aplicação representam o terreno comum entre princípios éticos e prática política no plano interno". (LAFER, 1995, p. 141).
} 
Assim, o indivíduo passa de uma compreensão individualizada, caracterizada apenas pela luta da própria sobrevivência, para uma perspectiva de que ser pertencente a uma comunidade e o reconhecimento dos seus direitos, parte da aceitação e reconhecimento prioritariamente dos direitos do outro. Isso quer dizer que, “[...] o indivíduo só pode se proporcionar um sentimento de garantia a respeito de ser reconhecido por seu parceiro de interação mediante a experiência da reação prática com que aquele responde a um desafio deliberado, ou mesmo a uma provocação". (HONNETH, 2003, p. 64). Desta forma, a luta por reconhecimento é concebida mais através dos elementos sociais do que propriamente elementos jurídicos, que se retrata em um despertar de consciência "no sentido de descentramento das formas individuais" para um "aumento de comunitarização", também colocado por Hegel como um processo de desenvolvimento do indivíduo "a partir da filosofia da consciência'. (HONNETH, 2003, p. 70).

Essa concepção de "filosofia da consciência" desenvolve-se em um processo que "[...] considera primeiro a relação do indivíduo consigo próprio, depois as relações institucionalizadas dos sujeitos entre si e por fim as relações reflexivas dos sujeitos socializados com o mundo em seu todo". (HONNETH, 2003, p. 72). Em uma reflexão dialógica mais crítica e contemporânea, partindo dessa ideal de conscientização, é possível transformar a dependência das lacunas de inefetividade de proteção de direitos, utilizando a ideia de que "a igreja, família e amigos são as principais fontes de solidariedade social. O Estado só deveria intervir quando essas instituições não cumprissem plenamente suas obrigações"11. (GIDDENS, 2005, p. 122). Nesse entendimento surge uma mudança cultural social que é compreendida nos direitos de terceira geração ou dimensão, que dizem respeito a fraternidade e solidariedade para efetivação dos direitos garantidos em primeira e segunda geração (direitos de liberdade e igualdade).

A fraternidade proposta não está atrelada a um aspecto em que a sociedade deve fazer as vezes do Estado, pois há direitos que só podem ser resguardados inerentemente pela soberania administrativa do governo. Contudo, há uma iminência de lacunas nos temas globais que não podem ser preenchidas com mais atribuições ao Estado, mas que deve ser compartilhada por uma consciência de solidariedade partindo da concepção consciente do indivíduo em efetivar

\footnotetext{
11 Anthony Giddens (2005) propõe uma ideia de nação cosmopolita, mas não deixa de reiterar as problemáticas decorrentes dessa nova perspectiva, desde a xenofobia enviesada através do nacionalismo, até os ideais de pluralismo cultural ou multiculturalismo. Considera desta forma que " a identidade nacional só pode ser uma influência benéfica se for tolerante à ambivalência, ou à múltipla afiliação. Indivíduos que são simultaneamente ingleses, britânicos, europeus, e têm algum senso abrangente de cidadania global, podem encarar uma de suas identidades como prioritária, mas isso não os impede necessariamente de aceitar também as outras". (p. 142).
} 
direitos em favor do outro. Nesse sentido, o reconhecimento se apresenta como um elemento que parte da subjetividade do indivíduo, mas que possui prospecções positivas quando colocadas em favor do outro. ${ }^{12}$

Diante disso, compreende-se que a luta por reconhecimento, propõe uma ressignificação da forma que enxergamos o outro, ou, como colocado por Bauman (1998), como enxergamos o estranho. Desse modo, o estranho é visto como a aquele que também amedronta pelo medo. Assim, o processo de reconhecer-se no outro propõe a quebra de paradigmas, uma consciência individual que reverbera no reconhecimento de um direito individual para uma prospecção alheia. Em se tratando de um reconhecimento do estrangeiro como sujeito de direitos, "[...] a luta por reconhecimento não somente contribui como elemento constitutivo de todo processo de formação para a reprodução do elemento espiritual da sociedade civil como influi também de forma inovadora sobre a configuração interna dela", ou seja, propõe um deslocamento a partir de uma compreensão de um direito individual, para o desenvolvimento do direito no contexto de intersubjetividade. (HONNETH, 2003, p. 95). Ou seja, quando "[...] dois indivíduos se vêem confirmados em sua autonomia por seu respectivo defrontante, eles podem chegar de maneira complementária a uma compreensão de si mesmos como um Eu autonomamente agente e individuado". (HONNETH, 2003, p. 120).

Ao se deparar com a questão dos refugiados, a luta por reconhecimento passa pelo processo de consciência, em que, o sujeito deve refletir a reais condições de quem solicita refúgio, de tal modo a ponto de vê-lo como pessoa dotada de direitos, tão quanto a si mesmo. Nesse sentido, “[...] um sujeito só pode adquirir uma consciência de si mesmo na medida em que ele aprende a perceber sua própria ação da perspectiva, simbolicamente representada, de uma segunda pessoa". (HONNETH, 2003, p. 131). Assim, esse processo se manifesta socialmente em favor de duas vertentes, do próprio sujeito que reconhece o direito do outro, a partir do sentimento comum do auto-respeito que é adquirido quando colocado em prática o respeito pelo outro e a partir da compreensão do outro em ter o seu direito reconhecido. É um comportamento que, como colocado por Hegel, entendido como solidário, e quando retificado por Honneth, indo além da solidariedade “porque ela partilha com o 'direito' o ponto de vista

\footnotetext{
12 O processo de reconhecimento, ainda que tenha pressupostos subjetivos que estão atrelados a subjetividade e voluntariedade do sujeito, como leciona Honneth (2003), "só se desenvolve até chegar a uma relação de amor real na medida em que é capaz de tornar-se um conhecimento das duas partes, intersubjetivamente partilhado; pois só quando todo sujeito vem a saber de seu defrontante que ele 'igualmente se sabe em seu outro', ele pode possuir a 'confiança' segura de que 'o outro' é 'para mim'. Para designar essa relação mútua de conhecer-se-nooutro, Hegel emprega agora, pela primeira vez, o conceito de 'reconhecimento': na relação amorosa, escreve ele em uma nota marginal, é o 'si não cultivado, natural', que é reconhecido"”. (HONNETH, 2003, p. 77).
} 
cognitivo do tratamento igual universal, mas com o 'amor', o aspecto do vínculo emotivo e da assistência”. (HONNETH, 2003, p. 153).

Assim, a luta por reconhecimento, é um processo, não é uma automática tomada de consciência repentina que atinge o indivíduo como um insight e muda toda a sua forma de agir no contexto social. Por isso o intenso diálogo da obra com a psicologia social, que parte de uma reflexão pessoal de como estão postos e garantidos os direitos para si e como eles podem ser reconhecidos para o outro, em forma de reconhecimento de um direito próprio. Estende-se aí a sua complexidade em se tratando de pessoas em situação de refúgio, pois, traz ao cenário de reconhecimento um sujeito distante da comunidade em que está inserida o próprio "Eu”, trazendo assim, um esforço e reflexão maior para compreender as necessidades do outro através de si mesmo.

Em um contexto jurídico, político e internacionalista que envolve a situação dos refugiados, o processo de reconhecimento individual demanda articulações em conjunto da sociedade. Deste modo, é indispensável que exista uma ampla divulgação e desmistificação de conceitos reproduzidos equivocadamente no meio social, para que se compreenda o real significado do instituto do refúgio. Isso porque, grande parte da dificuldade de inserção do refugiado no meio social, advém dos discursos estabelecidos por informações equivocadas, objeto de reproduções midiáticas desprovidas de conhecimento real do fenômeno.

Os instrumentos normativos e a atuação do Estado em conjunto com a sociedade civil tem extrema importância para atender as necessidades desse panorama, contudo, a efetividade da proteção dos refugiados a partir do reconhecimento propõe uma mudança de estado de consciência apenas em si, projetando-a em favor do outro. Ou seja, compreender que as nuances que envolvem os solicitantes de refúgio, podem envolver pessoas que até então, conseguem exercer livremente os seus direitos e manifestar as suas vontades. Porém, não está isento de, em um momento posterior, diante da dinâmica do sistema de proteção dos direitos humanos e da fragilidade de diversos sistemas políticos que organizam as nações, tal instituto não seja mecanismo hábil para quem um dia dele se utilizou em favor do outro.

\section{CONSIDERAÇÕES FINAIS}

A luta por reconhecimento proposta por Axel Honneth, demonstra-se como um processo adequado para atravessar as problemáticas sociais, porque está além das imposições normativas, e chama o sujeito de direitos para refletir sobre o que realmente se põe como 
direito a ele tutelado e como tais direitos se encontram garantidos e efetivados perante o seu semelhante. Através da simples observância ao não alcance de direitos pelo outro, em forma de reconhecimento, percebe-se que o direito próprio também se encontra negado, o que, consequentemente propõe uma mudança de comportamento frente ao desprezo a direitos a si também inerentes.

Nessa conjuntura, não se afasta os aspectos jurídicos e necessários para a boa convivência social, mas desperta a participação social que se vê, em um mundo cada vez mais individualista a importância do se sentir pertencente a uma comunidade, inclusive, de defender os direitos de quem ainda a ela não pertence. A organização geopolítica da comunidade internacional impõe uma consideração às fronteiras estabelecidas nessa ordem administrativa, porém, tais fronteiras não podem ser preponderantes e superiores a luta pela vida digna e adequada de seres humanos.

O elemento ensejador para os fluxos migratórios forçados, o fundado temor de perseguição e a maciça violação de direitos humanos não podem encontrar obstáculos para serem enfrentados, e através do processo de reconhecimento da sociedade em favor do outro, fronteiras são derrubadas. Isso porque, as mesmas são desconsideradas quando propõe instrumentos de desenvolvimento econômico, em que, países, ainda com planos políticos e ideologias totalmente antagônicas firmam parcerias visando atender interesses políticos do Estado. De igual forma, propõe a luta pelo reconhecimento a derrubada de fronteiras que suprimem o reconhecer do outro, como seu semelhante, ainda que nacional de uma cultura extremamente diferente, advindo de um país de continente diverso do qual o país está inserido, não deve persistir a compreensão de que existem fronteiras para o reconhecimento e proteção de direitos.

Assim a proposta da luta por reconhecimento encontra aplicabilidade no meio social para efetivação de direitos quando proporciona à sociedade um rompimento de comportamentos equivocados e reiterados, para uma nova concepção de composição social. Abre-se margem para que as pessoas possam refletir sobre a violação dos seus próprios direitos, posicionando-se também na restrição de direitos do seu semelhante. Nessa troca de mútuo reconhecimento, suprem-se as diversas lacunas em que os instrumentos estatais e legais não são capazes de suprir, devida a inerente necessidade de transformação por parte do indivíduo, tarefa que nenhuma estrutura de poder é capaz de cumprir. 


\section{REFERÊNCIAS}

ALMEIDA, Guilherme Assis de. Direitos humanos e não violência. 2. ed. São Paulo: Atlas, 2015

ARENDT, Hannah. A condição humana. 10. ed. Rio de Janeiro: Forense Universitária, 2007.

BARRETO, Luiz Paulo T. F. A Lei Brasileira de Refúgio - Sua história. In: Refúgio no Brasil: a proteção brasileira aos refugiados e seu impacto nas Américas. 1. ed. Brasília: ACNUR, Ministério da Justiça, 2010.

BAUMAN, Zygmunt. O mal-estar da pós-modernidade. - Rio de Janeiro: Jorge Zahar Ed., 1998.

BRASIL. Ministério da Justiça e Segurança Pública. Refúgio em Números. Brasília, 2017. Disponível em: <http://www.acnur.org/portugues/wp-content/uploads/2018/04/refugio-emnumeros_1104.pdf $>$. Acesso em: 15. Jun. 2018.

FERREIRA, Vanessa Capistrano. Debilidades do reconhecimento: inclusão e inferiorização em tempos de crise migratória. Revista Interdisciplinar de Direitos Humanos, v. 5, n. 1, p. 37-56, 2017.

GIDDENS, Anthony. A terceira via: Reflexões sobre o impasse político atual e o futuro da social-democracia. 5. ed. - Rio de Janeiro: Record, 2005.

HONNETH, Axel. Luta pelo reconhecimento: a gramática moral dos conflitos sociais. São Paulo: Ed. 34, 2003.

KANT, Immanuel. A paz perpétua. Tradução de Marco A. Zingano. 2. ed. Porto Alegre: L\&PM, 1989.

JABORANDY, Clara Cardoso Machado. O princípio jurídico da fraternidade: Um instrumento para proteção de direitos fundamentais Transindividuais. 1. ed. Rio de Janeiro: Lumen Juris, 2017.

LAFER, Celso. A soberania e os direitos humanos. Lua Nova, n. 35, p. 137-148, 1995.

LAFER, Celso. A reconstrução dos direitos humanos: um diálogo com o pensamento de Hannah Arendt. São Paulo: Companhia das Letras, 1988.

MACHADO, Igor. Imobilizações da Diferença e os Fantasmas de Controle: Reflexões Sobre a Produção Legislativa Recente Sobre Os Imigrantes No Brasil. In: Refúgio e Hospitalidade. GEDIEL, J; GODOY, G.(Org). Curitiba: Kairós, p. 209 - 230, 2016. 
PIOVESAN, Flávia. Internacionalização dos Direitos Humanos e Humanização do Direito Internacional: Desafios Contemporâneos. In: Boletim da Sociedade Brasileira de Direito Internacional, Belo Horizonte: Arraes Editores, 2017.

ONU. Carta das Nações Unidas, 1945.

SANTOS, Boaventura de Sousa; CHAUÍ, Marilena. Direitos Humanos, democracia e desenvolvimento. São Paulo: Cortez, 2013.

SEN, Amartya. A ideia de Justiça. São Paulo: Companhia das Letras, 2011.

SEN, Amartya. Desenvolvimento como liberdade. São Paulo: Companhia das Letras, 2010.

TRINDADE, Antônio Augusto Cançado; PEYTRIGNET, Gérard; DE SANTIAGO, Jaime Ruiz. As três vertentes da proteção internacional dos direitos da pessoa humana: Direitos Humanos, Direito Humanitário, Direito dos Refugiados. Instituto Interamericano de Direitos Humanos, 1996. Disponível em:

<https://www.icrc.org/por/resources/documents/misc/direitos-da-pessoa-humana.htm> Acesso em: 15 Jun. 2018.

\section{DADOS DA PUBLICAÇÃO}

Categoria: artigo submetido ao double-blind review.

Recebido em: 09/07/2018.

Aceito em: 12/08/2019. 
